\title{
Cooling Behavior and Slab Surface Quality in Continuous Casting with Alloy 718 Mold
}

\author{
A. YAMAUCHI, S. ITOYAMA, ${ }^{1)}$ Y. KISHIMOTO, ${ }^{1)}$ H. TOZAWA ${ }^{1)}$ and K. SORIMACHI ${ }^{21}$ \\ Technical Research Laboratories, Kawasaki Steel Corporation, Kawasaki-dori, Mizushima, Kurashiki 712-8511 Japan. \\ 1) Technical Research Laboratories, Kawasaki Steel Corporation, Kawasaki-cho, Chuo-ku, Chiba 260-0815 Japan. \\ 2) Research Laboratories, Kawasaki Refractories Co., Ltd., Aza-Higashioki, Nakahiro, Akoh, Hyogo 678-0232 Japan.
}

(Received on April 16, 2002; accepted in final form on June 17, 2002)

\begin{abstract}
In order to decrease surface defects of continuously cast slab, a newly designed innovative mold to realize uniform mild cooling has been developed. Nickel base super alloy, Alloy 718, characterized by high strength at elevated temperature and low thermal conductivity was applied as the material of mold plates instead of conventional copper. Casting experiments of medium carbon steel have been performed with pilot scale continuous caster. The following advantages of the new mold with $40 \%$ decrease of meniscus heat extraction and $75 \%$ decrease of its fluctuation were confirmed in comparison with conventional copper mold. 1) Index of longitudinal surface crack decreased by about $50 \%$, 2) Frequency of hook (over flow type oscillation marks) appearance on which non-metallic inclusions are likely entrapped decreased by $50 \%$, 3) Depth of "hook" decreased by 20 to $45 \%$, and 4) Average of oscillation mark depth decreased by $35 \%$ and its fluctuation also decreased by about $50 \%$.
\end{abstract}

KEY WORDS: continuous casting; mold; nickel alloy; mold flux; heat transfer; longitudinal crack; steel.

\section{Introduction}

In order to achieve and maintain high productivity in continuous casting, the development of a technology for preventing subsurface inclusion defects in ultra low carbon steel and longitudinal surface cracks in high speed casting of medium-carbon steel at casting speeds exceeding 2 $\mathrm{m} / \mathrm{min}$ has been particularly required. Because the origin of many surface layer defects in continuously cast slabs can be found in the initial stage of solidification, it is necessary to give special attention to initial solidification control technology as a measure for preventing this type of defect. Many reports on the mechanism of occurrence and preventive measures for various type of defects have been published since the $1970,{ }^{1-12)}$ and considerable effort has been devoted to clarifying the relationship between operating conditions and surface quality. As factors which have a major influence on the surface quality of slabs, these reports have mentioned cooling conditions in the mold, ${ }^{1-6)}$ the physical properties of the mold flux, ${ }^{7-9}$ mold oscillation conditions $^{10)}$ the amount of mold taper, ${ }^{11)}$ the flow of molten steel in the mold ${ }^{12)}$ and others. In particular, the importance of uniform mild cooling has been pointed out as a key factor in cooling in the mold.

Method of controlling initial stage solidification which achieve mild cooling includes adding a thermal resistance layer to the mold by processing the mold with grooves and increasing the thermal resistance of the mold plate itself by methods such as plating ${ }^{2-5)}$ applying an electromagnetic field in the vicinity of the meniscus ${ }^{6)}$ and others. Although these technologies have been shown to possess a certain degree of effectiveness, they have also following disadvantages that disturb the practical application. For example, the grooved mold poses problems of groove wear and the cost of processing and reworking, while in the case of thermal resistance layers applied to the mold wall surface, the thermal resistance layer tends to peel due to thermal stress at the interface with the mold material. The method of applying an electromagnetic field to the shell at meniscus region has been tested and was effective to reduce of $80 \%$ of surface defects for billet casting. ${ }^{6}$ However, application to slab casters has many technical problems, low efficiency of electromagnetic transmission over mold plate of broadface, for example.

Although uniform mild cooling using a high basicity, high solidification temperature mold flux has a long history of practical application, this type of mold flux reduces the thickness of the liquidus film, which has the harmful effect of deteriorating lubrication in the mold. In recent research, it has been reported that the thermal resistance at the interface between the copper mold plates and the mold flux film is of crucial importance in initial solidification. ${ }^{13-15)}$ However, in order to equalize the heat transfer that are mediated by mold flux, including the inflow of the mold flux, it is necessary to control or reduce the unevenness by some means other than the mold flux. As a conceivable method of accomplishing this, it is possible to realize a relative reduction in the unevenness of heat transfer in the mold by increasing the thermal resistance of the mold itself. The reasons for the choice of nickel base super alloy for materi- 


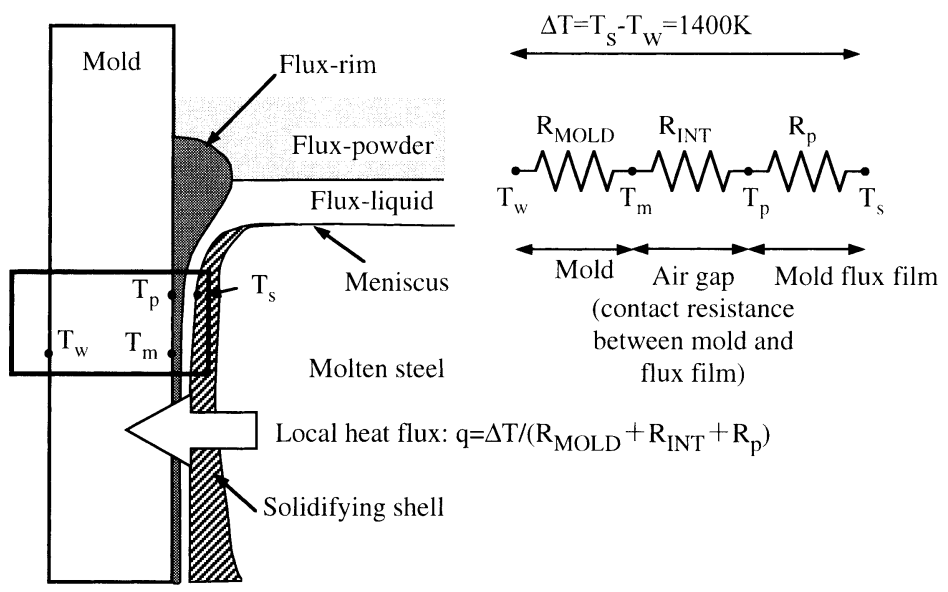

Fig. 1. Heat transfer model for estimation of air gap and flux film thickness immediately below meniscus in continuous casting mold.

al of the mild cooling mold in the present work are, 1) It does not require additional processing of the mold, 2) It does not have an interface between heterogeneous materials which may be an origin of cracks and 3) possesses low thermal conductivity and excellent high-temperature strength characteristics. The mild cooling mold was designed, fabricated and tested at a pilot plant of continuous caster. The effectiveness of mild cooling in reducing slab surface layer defects, particularly longitudinal cracks, was verified, and the heat extraction characteristics of the mold have been investigated.

\section{Design of Mold for Uniform Mild Cooling}

\subsection{Selection of Mold Material}

In order to suppress the surface cracks, various experiments ${ }^{2-5)}$ suggest that meniscus heat flux (In the following, mold heat flux refers to meniscus heat flux unless stated otherwise) is required to be approximately $70 \%$ of that of the $\mathrm{Cu}$ mold. Accordingly, the mold was designed in this work to realize a mold heat flux of $70 \%$ (approximately $1.79 \times 10^{6} \mathrm{~W} \mathrm{~m}^{-2}$ at a casting speed of $2.67 \times 10^{-4} \mathrm{~m} \mathrm{~s}^{-1}$ $(1.6 \mathrm{~m} / \mathrm{min}))$ of that of the $\mathrm{Cu}$ mold.

A fundamental study of one-dimensional heat transfer was carried out, as described below (Fig. 1). Mold heat flux, $q$, is expressed by Eq. (1) using the mold thermal resistance, $\mathrm{R}_{\mathrm{MOLD}}\left(7.6 \times 10^{-5} \mathrm{~m}^{2} \mathrm{~K} \mathrm{~W}^{-1}\left(0.076 \mathrm{~m}^{2} \mathrm{~K} / \mathrm{kW}\right)\right.$ in a $\mathrm{Cu}$ mold), the thermal resistance of an air gap, $\mathrm{R}_{\mathrm{INT}}$ (thermal resistance at the interface between the mold and the mold flux film), and the thermal resistance of the mold flux film, $R_{\mathrm{p}}$.

$$
q=\frac{T_{\mathrm{s}}-T_{\mathrm{w}}}{R_{\mathrm{MOLD}}+R_{\mathrm{INT}}+R_{\mathrm{P}}}
$$

Assuming the surface temperature of the solidified shell, $T_{\mathrm{s}}$, is $1773 \mathrm{~K}$, which is near the liquidus temperature of molten steel, and the temperature on the cooling-water-side of the mold, $T_{\mathrm{w}}$, is $373 \mathrm{~K}, q$ can be calculated if $R_{\mathrm{INT}}$ and $R_{\mathrm{p}}$ are known. As mentioned later in this paper, the maximum heat flux immediately below the meniscus in a $\mathrm{Cu}$ mold is 2.55 $\mathrm{MW} \mathrm{m}^{-2}$. Reverse calculation of $R_{\mathrm{INT}}+R_{\mathrm{p}}$ from Eq. (1) under this condition gives a result of $4.8 \times 10^{-4} \mathrm{~m}^{2} \mathrm{~K} \mathrm{~W}^{-1}$ $\left(0.48 \mathrm{~m}^{2} \mathrm{~K} / \mathrm{kW}\right)$. Holding $R_{\mathrm{INT}}+R_{\mathrm{p}}$ constant, the relation-

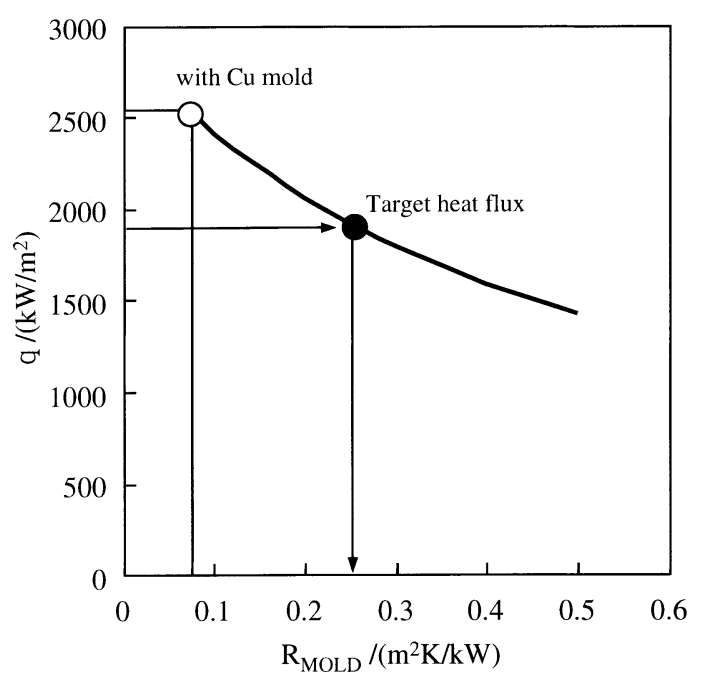

Fig. 2. Estimation of heat flux immediately below meniscus relative to $R_{\mathrm{MOLD}}$; assuming $R_{\mathrm{INT}}+R_{\mathrm{p}}=0.48 \mathrm{~m}^{2} \mathrm{~K} / \mathrm{kW}$ and Eq. (1).

ship between the heat flux, $q$, immediately under the meniscus and thermal resistance of the mold, $R_{\mathrm{MOLD}}$, can be obtained from Eq. (1), as shown in Fig. 2. The value of $R_{\mathrm{MOLD}}$ at which it is possible to obtain a value of $q$ equal to approximately of $70 \%$ that of the $\mathrm{Cu}$ mold is $2.4 \times 10^{-4} \mathrm{~m}^{2} \mathrm{~K}$ $\mathrm{W}^{-1}\left(0.24 \mathrm{~m}^{2} \mathrm{~K} / \mathrm{kW}\right)$. When $q=1.79 \mathrm{MW} \mathrm{m}^{-2}$, the temperature difference $\Delta T_{\mathrm{m}}\left(=q \cdot R_{\mathrm{MOLD}}\right)$ between the cooling water side and the slab side of the mold is $717 \mathrm{~K}$. The surface temperature of the mold can be estimated at approximately $T_{\mathrm{w}}+\Delta T_{\mathrm{m}}=1090 \mathrm{~K}$. A key point in the design was to minimize as much as possible the thermal stress generated in the mold material under this condition. Moreover, it was essential to satisfy several conditions, including 1) excellent high-temperature strength $(0.2 \%$ proof stress is greater than maximum thermal stress), 2) low thermal conductivity (to reduce heat flux), 3) low coefficient of thermal expansion (to reduce thermal stress), and 4) thick mold plates (to reduce thermal stress). Therefore, one of precipitation strengthened Ni group alloys, Alloy 718, has been selected as the mold material, based on the results of various study. Table 1 shows the properties of Alloy 718 and $\mathrm{Cu}$. Table 2 shows the chemical composition of Alloy 718 . 


\subsection{Structure of Alloy 718 Mold}

The distance from the end ends of the cooling slits to the inner wall of the mold, $d_{\mathrm{m}}$, was set at $3.9 \mathrm{~mm}$ based on the

Table 1. Properties of mold materials.

\begin{tabular}{cccccc}
\hline $\begin{array}{l}\text { thermal expansion } \\
\text { coefficient } \\
\left(\times 10^{-7} \mathrm{~K}\right)\end{array}$ & $\begin{array}{l}\text { thermal } \\
\text { conductivity } \\
(\mathrm{W} / \mathrm{mK})\end{array}$ & $\begin{array}{l}\text { thermal } \\
\text { diffusivity } \\
\left(\times 10^{6} \mathrm{~m}^{2} / \mathrm{s}\right)\end{array}$ & $\begin{array}{l}\text { solidus and } \\
\text { liquidus Temp. } \\
(\mathrm{K})\end{array}$ & $\begin{array}{l}0.2 \% \\
\text { proof stress } \\
(\mathrm{MPa})\end{array}$ \\
\hline $\mathrm{Cu}$ & $\begin{array}{c}180 \\
\text { (at } 273 \text { to } 573 \mathrm{~K})\end{array}$ & $\begin{array}{l}330 \\
(\text { at } 473 \mathrm{~K})\end{array}$ & 92.8 & 1356 & $\begin{array}{l}274-412 \\
\text { (at 653K) }\end{array}$ \\
\hline $\begin{array}{l}\text { Alloy } 718 \\
\text { at } 1033 \mathrm{~K}\end{array}$ & 149 & 17.9 & 3.97 & $1533-1608$ & 799 \\
\hline
\end{tabular}

Table 2. Chemical composition of Alloy 718. (mass\%)

\begin{tabular}{c|c|c|c|c|c|c}
\hline $\mathrm{Ni}$ & $\mathrm{Cr}$ & $\mathrm{Mo}$ & $\mathrm{Fe}$ & $\mathrm{Nb}+\mathrm{Ta}$ & $\mathrm{Al}$ & $\mathrm{Ti}$ \\
\hline 52.6 & 19.0 & 3.0 & 19.0 & 5.0 & 0.5 & 0.9 \\
\hline
\end{tabular}

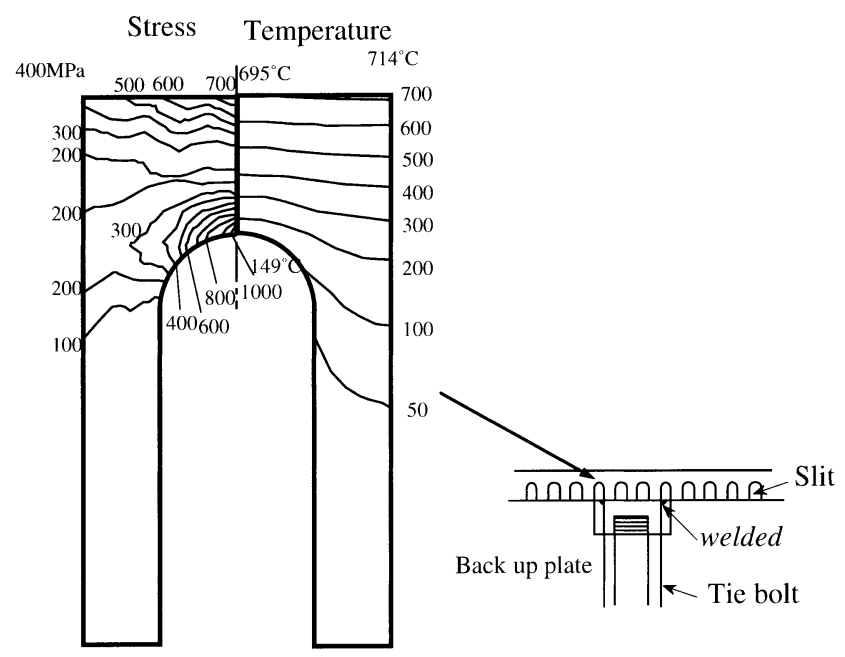

(a) Stress distribution of water slit zone

(b) Temperature distribution of water slit zone

Fig. 3. Results of thermal stress analysis for Alloy 718 mold (distance from tip of slit and mold hot face, $3.9 \mathrm{~mm}$ ). thermal conductivity of Alloy $718, \lambda_{718}$ (although the thermal conductivity of Alloy 718 shows temperature dependence, here, a value of $16.5 \mathrm{~W} \mathrm{~m}^{-1} \mathrm{~K}^{-1}$ was used) and the design target value of $R_{\mathrm{MOLD}}\left(0.24 \mathrm{~m}^{2} \mathrm{~K} / \mathrm{kW}\right)$. Thermal stress has been checked by a thermal stress analysis (MARC) in Fig. 3, confirming that no cracking will occur during casting. The temperature of the mold surface immediately below the meniscus is approximately $823 \mathrm{~K}$ at a casting speed of $2.67 \times 10^{-4} \mathrm{~m} \mathrm{~s}^{-1}(1.6 \mathrm{~m} / \mathrm{min})$ under this condition, and exceeds $973 \mathrm{~K}$ at a casting speed of $4.17 \times 10^{-4} \mathrm{~m} \mathrm{~s}^{-1}(2.5 \mathrm{~m} / \mathrm{min})$ (Fig. 3(b)). The specification of the cooling slits were therefore decided in such a way that the calculated thermal stress in all parts of the mold would not exceed the $0.2 \%$ proof stress of the mold material at high-temperature (Fig. 3(a)). Because the mold plates were $18 \mathrm{~mm}$ thickness, it was not possible to cut taps directly in the mold plates, as is done with conventional $\mathrm{Cu}$ molds. Alloy 718 nuts were welded to span the slits, and the Alloy 718 mold plates were mounted using these nuts and tie bolts (Fig. 4(a)). The structure of the $\mathrm{Cu}$ mold used with the laboratory continuous caster for the comparison is shown in Fig. 4(b), and the basic specifications of the molds are given in Table 3. Both molds were constructed using the same material on all four sides, but in the case of the Alloy 718 mold, the depth of cooling slits was modified in the casting direction in order to maintain a uniform mold surface temperature.

\section{Casting Experiments with Laboratory Continuous Caster}

The basic casting conditions are shown in Table 4. In these experiments, the conditions were mainly selected to deliberately encourage longitudinal cracking in order to confirm the effectiveness of mild cooling in suppressing cracking. The steel grade used in casting was medium-carbon steel (approximately $0.11 \% \mathrm{C}$ ) that is sensitive to cracking. The major properties of the mold flux such as ba-

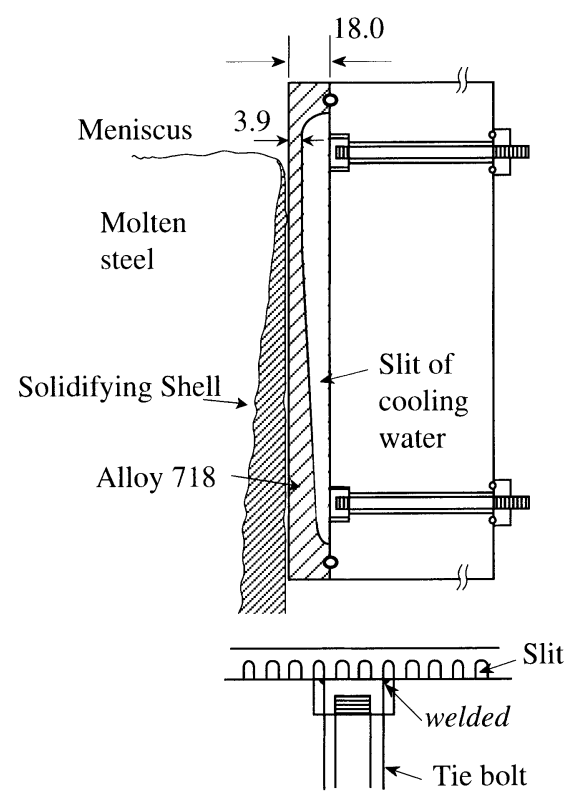

(a) Alloy 718 mold

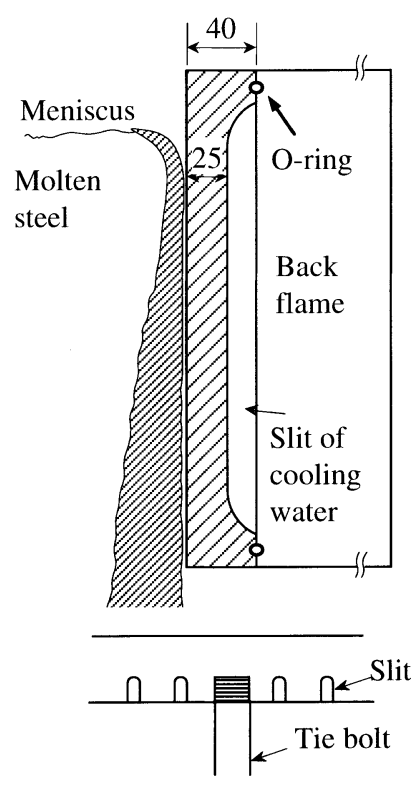

(b) $\mathrm{Cu}$ mold

Fig. 4. Schematic representation of longitudinal and cross sections of pilot caster molds. 
Table 3. Specification of molds.

\begin{tabular}{lcc}
\hline Length & $: 700 \mathrm{~mm}$ \\
Mold size & $: 110 \mathrm{~mm} \times 400 \mathrm{~mm}$ \\
Material and & \\
Thickness of mold plate : Alloy 718 & $18 \mathrm{~mm}$ \\
\multicolumn{4}{c}{$\mathrm{Cu}$} & $40 \mathrm{~mm}$ \\
Type of cooling & $:$ Slit (5mm width) \\
\hline
\end{tabular}

Table 4. Casting conditions.

\begin{tabular}{c|c|c|c|c|c}
\hline $\begin{array}{l}\text { Mold } \\
\text { material }\end{array}$ & $\begin{array}{l}\text { Casting } \\
\text { speed } \\
(\mathrm{m} / \mathrm{min})\end{array}$ & $\begin{array}{l}\text { Mold } \\
\text { frequency } \\
(\mathrm{cpm} / \mathrm{Hz})\end{array}$ & $\begin{array}{l}\text { Oscillation } \\
\text { stroke } \\
(\mathrm{mm})\end{array}$ & $\begin{array}{l}\text { Negative } \\
\text { strip time } \\
(\mathrm{sec})\end{array}$ & $\begin{array}{l}\text { Superheat in } \\
\text { tundish(K) }\end{array}$ \\
\hline $\mathrm{Cu}$ & 0.8 & $56 / 0.93$ & 7.8 & 0.302 & 28 \\
\hline Alloy 718 & 1.6 & $112 / 1.87$ & 7.8 & 0.153 & 30 \\
& 0.8 & $56 / 0.93$ & 7.8 & 0.302 & 19 \\
& 1.6 & $112 / 1.87$ & 7.8 & 0.153 & 33 \\
\hline
\end{tabular}

sicity, solidification temperature, and viscosity (at $1573 \mathrm{~K}$ ) are $0.94,1173 \mathrm{~K}$, and $0.09 \mathrm{~Pa} \cdot \mathrm{s}$ ( 0.9 Poise), respectively. In each casting experiment with the laboratory caster, $5.0 \times 10^{3}$ $\mathrm{kg}$ of molten steel were cast into a slab approximately $14 \mathrm{~m}$ in length. The temperature of the molten steel in the tundish was $1827 \mathrm{~K}$ at casting start and $1817 \mathrm{~K}$ at the completion of casting, and the average superheat of the molten steel was $28 \mathrm{~K}$. Considering the low thermal conductivity of the mold walls, a two-hole submerged entry nozzle with a downward inclination of $60^{\circ}$ and no well was adopted in order to ease the impact of the molten steel against the mold walls at the start of teeming. During casting, the meniscus was controlled automatically to a position, 100 $\mathrm{mm}$ from the top edge of the mold, at all times by an eddy current type of level sensor. A total number of $92 \mathrm{~K}$-type thermocouples were buried in the mold plates to measure the surface temperatures of the mold and the local heat flux. The interval of the temperature measurements was one second.

Four experimental levels were selected using the conditions shown in Table 4, comprising two mold material levels $(\mathrm{Cu}$, Alloy 718$)$ and two casting speed levels $(0.8$ and $1.6 \mathrm{~m} / \mathrm{min}$ ). The effect of mild cooling in the hold on the following items was studied; 1) Heat removal distribution obtained from mold temperature measurements, 2) surface properties of slabs, and 3) solidification structure and oscillation marks of slabs.

\section{Results of Casting Experiments with Laboratory Continuous caster}

\subsection{Mold Heat Extraction}

Comparisons of the heat removal characteristics and the surface temperature of the mold plates between the Alloy 718 mold and $\mathrm{Cu}$ mold at a casting speed of $2.67 \times 10^{-2} \mathrm{~m}$ $\mathrm{s}^{-1}(1.6 \mathrm{~m} / \mathrm{min})$ are shown in Figs. 5 and $\mathbf{6}$, respectively. The range of deviation in heat removal in Fig. 5 has an average value of $\pm 2 \sigma$ (standard deviation of time axis) over four minutes for the results of heat flux measurements taken at intervals of one second. The values of $2 \sigma$ with the $\mathrm{Cu}$ mold and the Alloy 718 mold at the peak heat flux immediately under the meniscus were 1.51 and $0.06 \mathrm{MW} \mathrm{m}^{-2}$, respectively. These results indicate that the heat removal

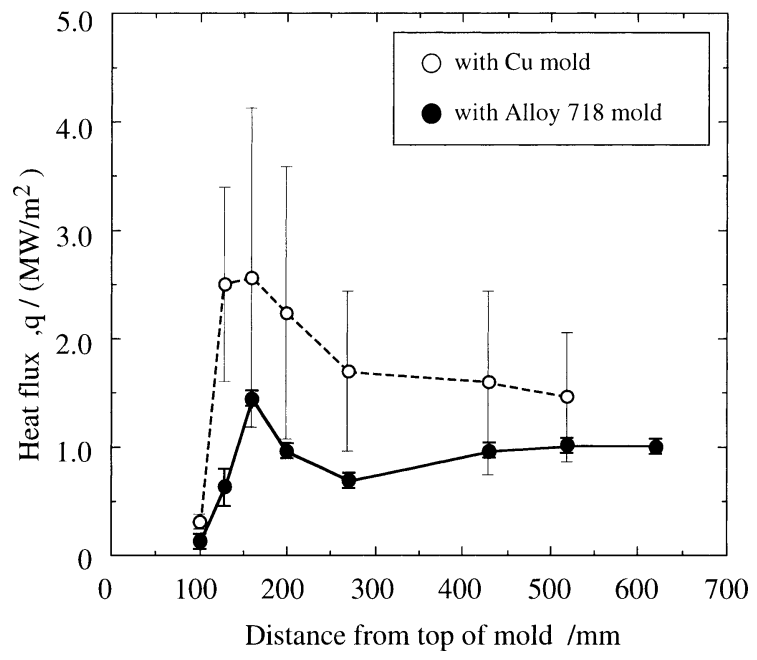

Fig. 5. Influence of mold material on axial heat-flux profiles and variation of heat flux at center plane of broad face (plots for average; error bars for $\pm 2 \sigma$; casting speed, 1.6 $\mathrm{m} / \mathrm{min})$.

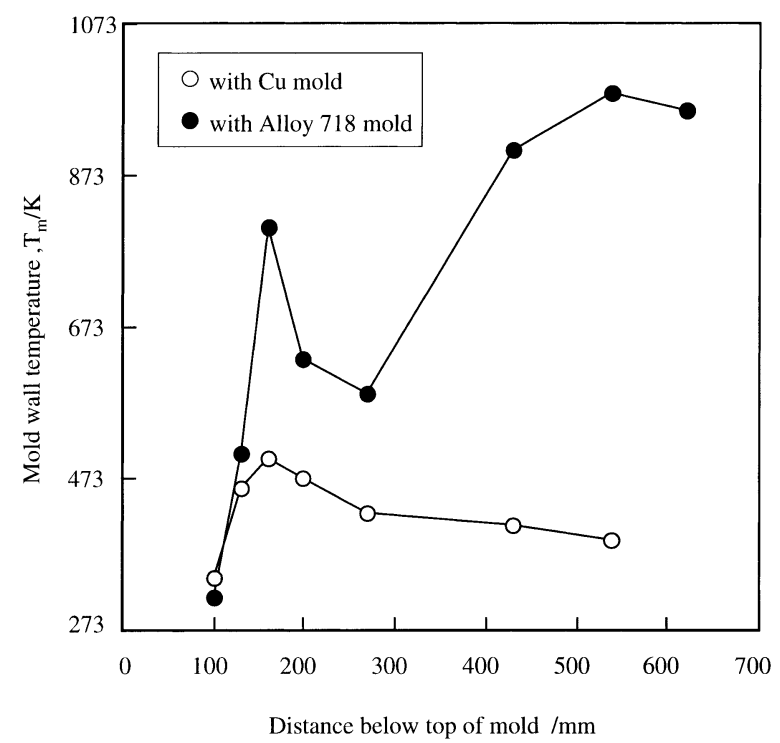

Fig. 6. Influence of mold material on axial temperature profiles of broad face mold wall estimated from measurement of mold wall temperature (plots for average; casting speed, $1.6 \mathrm{~m} / \mathrm{min})$.

characteristics of the Alloy 718 mold were substantially as designed and confirmed that the Alloy 718 mold possesses the following distinctive feature:

1) Mild cooling was realized, with heat removal at approximately $60 \%$ of the level with the Cu mold, both at the meniscus $(30 \mathrm{~mm}$ below the surface of the molten metal) and at an average value in the casting direction of the mold.

2) In comparison with the $\mathrm{Cu}$ mold, heat removal showed a remarkably smaller deviation.

To confirm the mild cooling effect, the secondary dendrite arm spacing was measured at a position $1.5 \mathrm{~mm}$ below the slab surface (Fig. 7). The cooling rate was calculated from the relational equation proposed by Suzuki et al. ${ }^{17)}$ as also shown in the Fig. 7. These results confirmed the mild cooling effect of the Alloy 718 mold. 


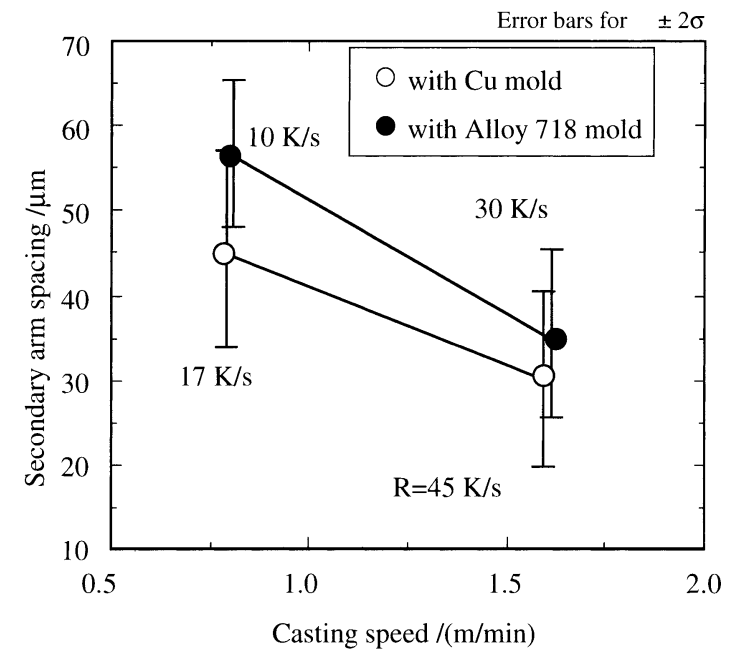

Fig. 7. Influence of mold material on secondary dendrite arm spacing and cooling rate, $R, 1.5 \mathrm{~mm}$ below slab surface.

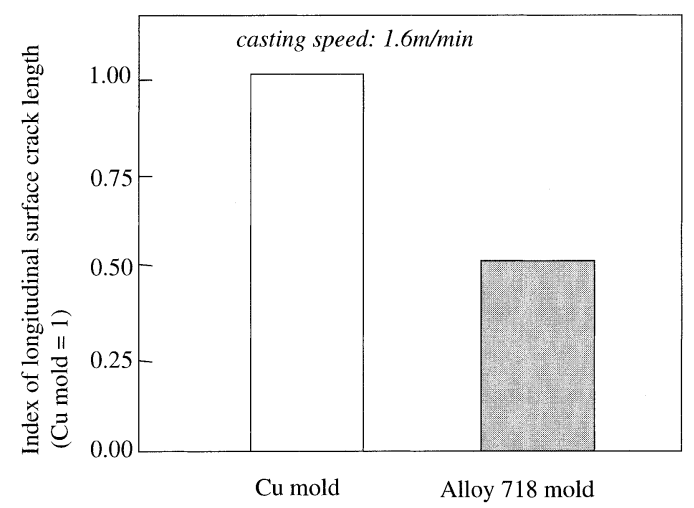

Fig. 8. Effect of mild cooling on frequency of longitudinal surface cracks.

\subsection{Effect of Alloy 718 Mold in Preventing Longi- tudinal Cracks}

Because virtually no cracking was observed at a casting speed of $1.33 \times 10^{-2} \mathrm{~m} \mathrm{~s}^{-1}(0.8 \mathrm{~m} / \mathrm{min})$ regardless of the mold materials, the following will discuss the results with slabs cast at $2.67 \times 10^{-2} \mathrm{~m} \mathrm{~s}^{-1}(1.6 \mathrm{~m} / \mathrm{min})$. Longitudinal cracks were found on the slab cast with the Alloy 718 mold, but were scattered at several places on one side of the slab. On the other hand, numerous cracks that accompanied depression were observed on the surface of the slab cast with the $\mathrm{Cu}$ mold, including some with a length of more than 1 $\mathrm{m}$. In order to evaluate the effectiveness of the Alloy 718 mold in suppressing longitudinal cracks, the ratio of the length of the cracks to the obtained length of the slab was defined as the index of the longitudinal surface crack length. The result of this evaluation is shown in Fig. 8. With the Alloy 718 mold, the crack length index was reduced by approximately $50 \%$ in comparison with the $\mathrm{Cu}$ mold, confirming the effectiveness of the mild cooling mold in preventing longitudinal cracks.

\subsection{Influence of Mold Material on Oscillation Mark Morphology}

An investigation of oscillation marks on the slab surface was carried out at the narrow side and at a position $80 \mathrm{~mm}$ from the corner on the inner radius side. Examples of the

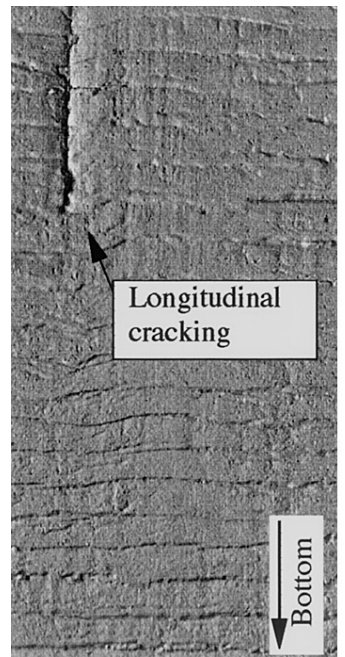

with $\mathrm{Cu}$ mold

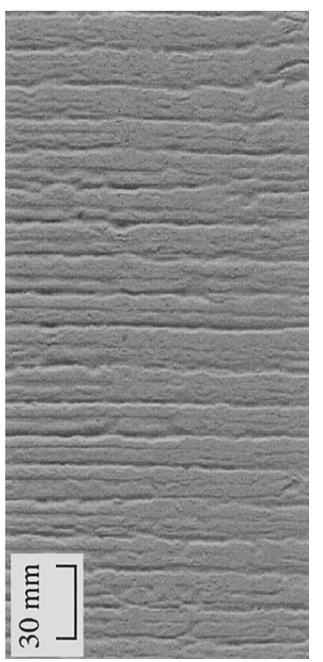

with Alloy 718 mold
Fig. 9. Appearance of oscillation marks on slab surface.

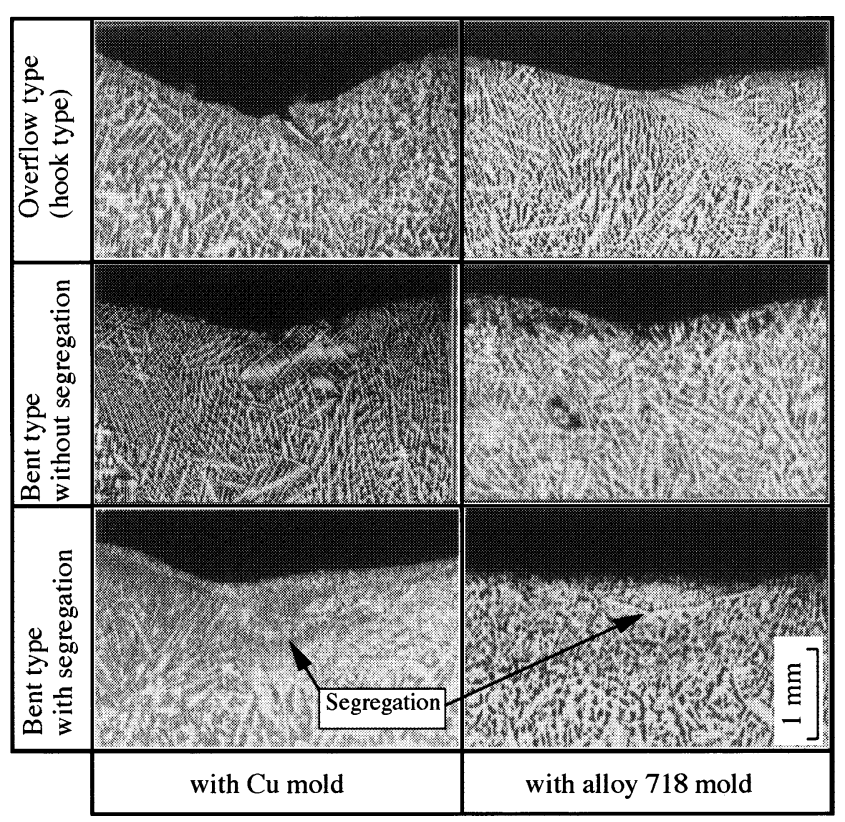

Fig. 10. Influence of mild cooling on microstructure of longitudinal cross section at casting speed of $1.6 \mathrm{~m} / \mathrm{min}$.

appearance of slabs produced with the respective molds are shown in Fig. 9. A characteristic feature of casting with the $\mathrm{Cu}$ mold is deep, sharp oscillation mark. On the other hand, the appearance of oscillation mark in casting with Alloy 718 mold is smooth and relatively shallow.

In the investigation of the solidification structure of the oscillation mark, longitudinal-sections of surface layer samples were polished and then etched with an aqueous solution containing $50 \%$ picric acid. Oscillation mark can be classified into the overflow type, which is accompanied by an inward collapse of the shell (hook), and the bent type, which is not accompanied by hooks. As shown in Fig. 10, both types were found in all samples. The bent type can be further classified into two types, depending on the presence or absence of segregation.

a) Overflow Type

As shown in Fig. 11, the rate of occurrence of overflow 


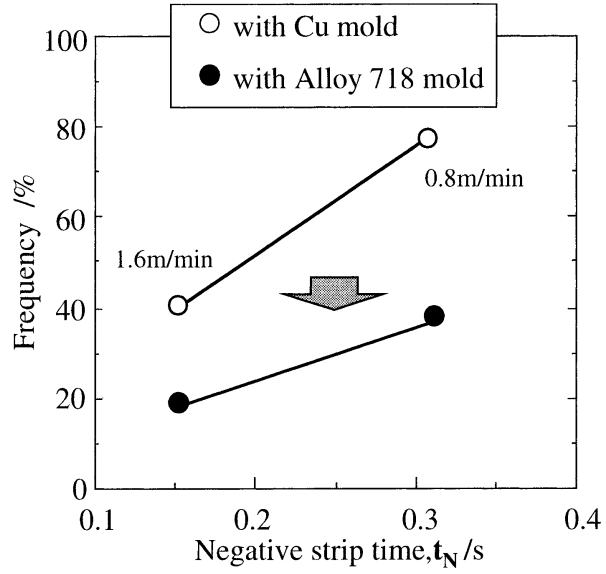

Fig. 11. Influence of mold material on frequency of hooks. (Frequency is the number of observed hooks divided by number of observed oscillation marks.)

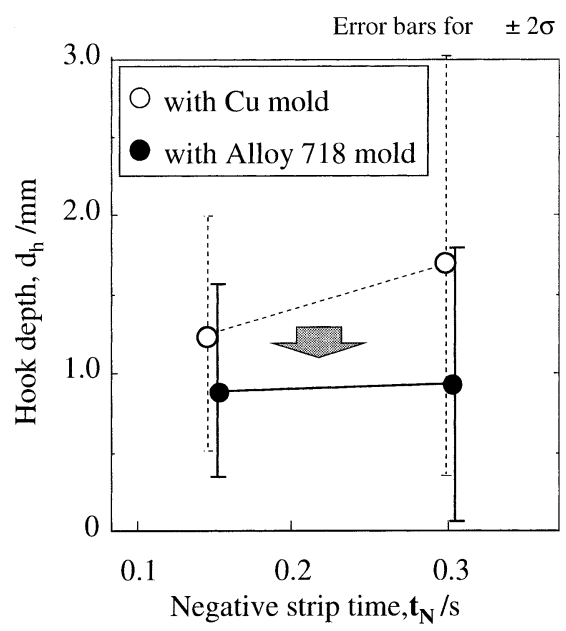

Fig. 12. Influence of mold material on hook depth.

type (frequency of hooks) in the slab produced with the Alloy 718 mold was approximately $50 \%$ of that of the $\mathrm{Cu}$ mold slab, indicating that the rate of occurrence of hooks is suppressed by mild cooling. Further, as shown in Fig. 12, the hook depth itself was also reduced by $30-40 \%$ by mild cooling. This improvement, combined with the reduction in the rate of occurrence, can be expected to have a large effect in preventing defects caused by oscillation mark hooks.

\section{b) Bent Type}

The relationship between the depth of bent type oscillation mark, defined as the sum of the concave of the slab surface due to oscillation and the thickness of surface segregation, and negative strip time, $t_{\mathrm{N}}$, is shown in Fig. 13. Both the average value and the deviation of the oscillation mark depth were reduced with the Alloy 718 mold.

\section{Discussion}

\subsection{Influence of Mold Material on Time-average Heat Flux at Meniscus}

The time-average heat extraction at the meniscus, obtained by casting experiments with the Alloy 718 mold, was approximately $60 \%$ of that of the $\mathrm{Cu}$ mold, as was shown in

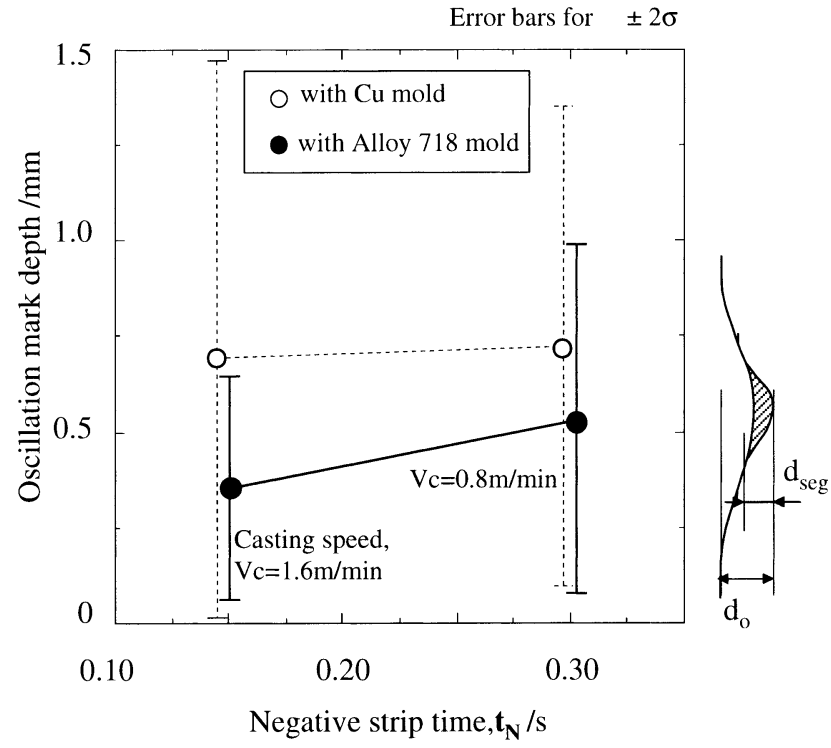

Fig. 13. Influence of mold material on bend type oscillation mark depth.

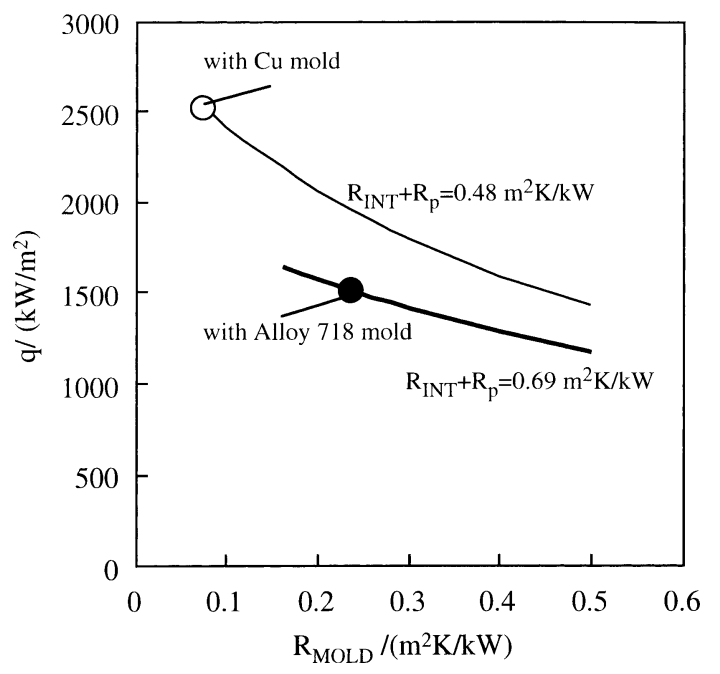

Fig. 14. Comparison of observed and calculated heat flux immediately below meniscus. (Curves were calculated from estimated $R_{\mathrm{INT}}+R_{\mathrm{p}}$ and Eq. (1).)

Fig. 5. However, the initial estimation, which considered only the contribution of the increase thermal resistance of the mold, was $70 \%$ of conventional heat flux as shown in Fig. 2. In order to account for this difference, it was necessary to examine factors in mild cooling other than the mold, using the one-dimensional steady heat transfer model shown in Fig. 1.

As previously mentioned, when the maximum heat flux immediately below the meniscus in a $\mathrm{Cu}$ mold is $2.55 \mathrm{MW}$ $\mathrm{m}^{-2}$, a value of $0.48 \mathrm{~m}^{2} \mathrm{~K} / \mathrm{kW}$ can be obtained for $R_{\mathrm{INT}}+R_{\mathrm{p}}$ by reverse calculation from Eq. (1). With $R_{\mathrm{INT}}+R_{\mathrm{p}}=0.48 \mathrm{~m}^{2}$ $\mathrm{K} / \mathrm{kW}$ held constant, the relationship between the heat flux, $q$, immediately below the meniscus and the thermal resistance of the mold, $R_{\mathrm{MOLD}}$, for various values of $R_{\mathrm{MOLD}}$ was obtained from Eq. (1), as shown in Fig. 14.

From Fig. 1, it can be understood that the interface temperature of the mold flux film, $T_{\mathrm{p}}$, is higher than the mold surface temperature by $q \cdot R_{\mathrm{INT}}$. However, on the other hand, $T_{\mathrm{p}}$ must always be smaller than the solidification tempera- 
ture of mold flux, $T_{\mathrm{f}}$, in order to maintain a positive value of $R_{\mathrm{INT} \cdot}{ }^{15)}$

$$
T_{\mathrm{p}}=T_{\mathrm{m}}+q \cdot R_{\mathrm{INT}}<T_{\mathrm{f}}
$$

Accordingly, $R_{\mathrm{INT}}<\left(T_{\mathrm{f}}-T_{\mathrm{m}}\right) / q$ is obtained, and there is an upper limit, $R_{\max }$, on the possible values of $R_{\mathrm{INT}}$. Because the $T_{\mathrm{f}}$ used in casting is $1173 \mathrm{~K}$, when the values of $q$ and $T_{\mathrm{m}}$ of the respective molds are obtained from Figs. 5 and 6 and used to calculate $R_{\max }$, the values of $R_{\max }$ for the $\mathrm{Cu}$ mold and Alloy 718 mold are 0.27 and $0.24 \mathrm{~m}^{2} \mathrm{~K} / \mathrm{kW}$, respectively. In the case of casting with the $\mathrm{Cu}$ mold, $R_{\mathrm{INT}}$ is reportedly equivalent to an air layer thickness of $10 \mu \mathrm{m}$ $\left(0.16 \mathrm{~m}^{2} \mathrm{~K} / \mathrm{kW}\right){ }^{7)}$

Further, assuming the thermal conductivity of the mold flux film is approximately $1.0 \mathrm{~W} \mathrm{~m}^{-1} \mathrm{~K}^{-1},{ }^{15)}$ and considering the fact that $R_{\mathrm{INT}}+R_{\mathrm{p}}=0.48 \mathrm{~m}^{2} \mathrm{~K} / \mathrm{kW}$ in the case of the $\mathrm{Cu}$ mold, $0.48 \geq R_{\mathrm{p}} \geq 0.48-0.27 \mathrm{~m}^{2} \mathrm{~K} / \mathrm{kW}$, and the thickness of the mold flux film is expected to be in the range between 210 and $480 \mu \mathrm{m}$. On the other hand, when an analysis using Eq. (1) was considered for the Alloy 718 mold in the same manner as for the $\mathrm{Cu}$ mold, a value of $R_{\mathrm{INT}}+R_{\mathrm{p}}=0.69 \mathrm{~m}^{2}$ $\mathrm{K} / \mathrm{kW}$ was obtained. This means that $R_{\mathrm{INT}}+R_{\mathrm{p}}$ increased because of an increase in the mold thermal resistance and a rise in the mold surface temperature $\left(T_{\mathrm{m}}=823 \mathrm{~K}\right)$. However, the $0.21 \mathrm{~m}^{2} \mathrm{~K} / \mathrm{kW}$ increase in $R_{\mathrm{INT}}+R_{\mathrm{p}}$ in comparison with the $\mathrm{Cu}$ mold was larger than the increment of $0.164 \mathrm{~m}^{2}$ $\mathrm{K} / \mathrm{kW}$ attributable to the $R_{\mathrm{MOLD}}$ of Alloy 718 . In other words, this contribution to mild cooling exceeded that of the mold itself. Given the increase in $T_{\mathrm{m}}$ and an $R_{\max }$ of 0.24 $\mathrm{m}^{2} \mathrm{~K} / \mathrm{kW}$ (equivalent to a gap of $15 \mu \mathrm{m}$ ), the possible values of $R_{\mathrm{INT}}$ were limited to a narrow range. Thus, from the fact that $0.69 \geq R_{\mathrm{p}} \geq 0.69-0.24 \mathrm{~m}^{2} \mathrm{~K} / \mathrm{kW}$, the thickness of the mold flux film is expected to be in the range between 450 and $690 \mu \mathrm{m}$. It can therefore be inferred that virtually all of the increase in $R_{\mathrm{INT}}+R_{\mathrm{p}}$, compared with case of the $\mathrm{Cu}$ mold, is attributable to an increase in $R_{\mathrm{p}}$, and the value of $R_{\mathrm{p}}$ corresponds to an increase of $150 \mu \mathrm{m}$ in the film thickness.

At the same time, mold flux film consumption was also measured. Values of 0.31 and $0.36 \mathrm{~kg} / \mathrm{slab}-\mathrm{m}^{2}$ were found for the $\mathrm{Cu}$ mold and Alloy 718 mold, respectively, which was a $0.05 \mathrm{~kg} / \mathrm{slab}-\mathrm{m}^{2}$ increase with the Alloy 718 mold. However, if this value is converted to the thickness of a uniform liquid film covering $1 \mathrm{~m}^{2}$ of slab surface, the result is $34 \mu \mathrm{m}$, which does not agree with the inferred value of 150 $\mu \mathrm{m}$. It is therefore appropriate to think that the solid phase mold flux film (adhering layer) at the meniscus increased. The cause is thought to be either an increase in the temperature of the mold surface or a decrease in the strength of the solidified shell. However, further study will be required to clarify the actual mechanism.

\subsection{Discussion of Fluctuation over Time in Heat Removal at Mold Meniscus}

Although it is reasonable to think that the prevention of cracks is attributable to a reduction in internal stress in the solidified shell resulting from uniform cooling, ${ }^{1)}$ the characteristics of fluctuation in heat removal with Alloy 718 mold will be examined here. In the heat transfer model (Fig. 1), the factor which causes fluctuation in the heat flux is assumed $R_{\mathrm{INT}}+R_{\mathrm{p}}$. Considering the fluctuation over time in $R_{\mathrm{INT}}+R_{\mathrm{p}}, \Delta R$, the difference in the heat flux before and after such fluctuation, $\Delta q$, is derived from Eq. (1) as shown in Eq. (3):

$$
\Delta q=\frac{\left(T_{\mathrm{s}}-T_{\mathrm{w}}\right) \cdot \Delta R}{\left(R_{\mathrm{MOLD}}+R_{\mathrm{INT}}+R_{\mathrm{p}}\right) \cdot\left(R_{\mathrm{MOLD}}+R_{\mathrm{INT}}+R_{\mathrm{p}}+\Delta R\right)}
$$

As shown in Fig. 5, $\Delta q=2 \sigma=1.50 \mathrm{MW} \mathrm{m}^{-2}$ with the $\mathrm{Cu}$ mold; therefore, $R_{\mathrm{INT}}+R_{\mathrm{p}}=0.48 \mathrm{~m}^{2} \mathrm{~K} / \mathrm{kW}$ (assuming $R_{\mathrm{INT}}=$ $0.16 \mathrm{~m}^{2} \mathrm{~K} / \mathrm{kW}$, then $\left.R_{\mathrm{p}}=0.32 \mathrm{~m}^{2} \mathrm{~K} / \mathrm{kW}\right), R_{\mathrm{MOLD}}=0.076 \mathrm{~m}^{2}$ $\mathrm{K} / \mathrm{kW}$, and $\Delta R=0.83 \mathrm{~m}^{2} \mathrm{~K} / \mathrm{kW}$ can be obtained from Eq. (3). On the other hand, in the case of the Alloy 718 mold, $\Delta q=60 \mathrm{~kW} / \mathrm{m}^{2}$, which is extremely small in comparison with that of the $\mathrm{Cu}$ mold, being less than $1 / 20$ of the value with the $\mathrm{Cu}$ mold. As the reason for this difference, it can easily be pointed out that there is large difference in the temperature response at the temperature measurement position, which is determined by the thermal resistance of the mold. The following will consider to what degree the fluctuations in the mold surface temperature reach the insertion position of the thermocouples.

Equation (4) is a differential equation expressing one-dimensional transient heat transfer, where $T$ is the temperature in the mold, $x$ is the mold thickness direction, and $\alpha$ is the thermal diffusivity of the mold material.

$$
\frac{\partial T}{\partial t}=\alpha\left(\frac{\partial^{2} t}{\partial x^{2}}\right)
$$

Solving Eq. (4) with a boundary conditions $T(0,0)=T_{0}$, $T(d, 0)=T_{d}$,

$$
T(x, t)=T_{d}+\left(T_{0}-T_{d}\right)\left\{1-\operatorname{erf}\left(\frac{x}{2 \sqrt{\alpha t}}\right)\right\} \ldots \ldots \ldots . . .(5)
$$

If it is assumed that the mold wall surface temperature at the mold temperature measurement position corresponds to the mold oscillation frequency, $f$, and fluctuates cyclically with an amplitude of $A$ around an average temperature of $T_{\text {avg, }}$

$$
T_{0}=T_{\mathrm{avg}}+A \cdot \sin (2 \pi f t)
$$

From Eqs, (5) and (6), the cyclical fluctuation component $\gamma$ of the temperature at position $x$ in the mold plate can be expressed by Eq. (7), when $A \cdot \sin (2 \pi f t) \neq 0$,

$$
\gamma(x)=A \cdot \sin (2 \pi f t)\left\{1-\operatorname{erf}\left(\frac{x}{2 \sqrt{\alpha t}}\right)\right\}
$$

Accordingly, damping ratio $\beta$ relative to the input fluctuation component is

$$
\beta=\frac{\gamma(x)}{\gamma(0)}=1-\operatorname{erf}\left(\frac{x}{2 \sqrt{\alpha t}}\right)
$$

Here, if the $\beta$ of $\mathrm{Cu}$ and Alloy 718 are compared for the case when it is $0.536 \mathrm{~s}$, which is the mold oscillation period $(1 / f=0.536 \mathrm{~s})$, then 


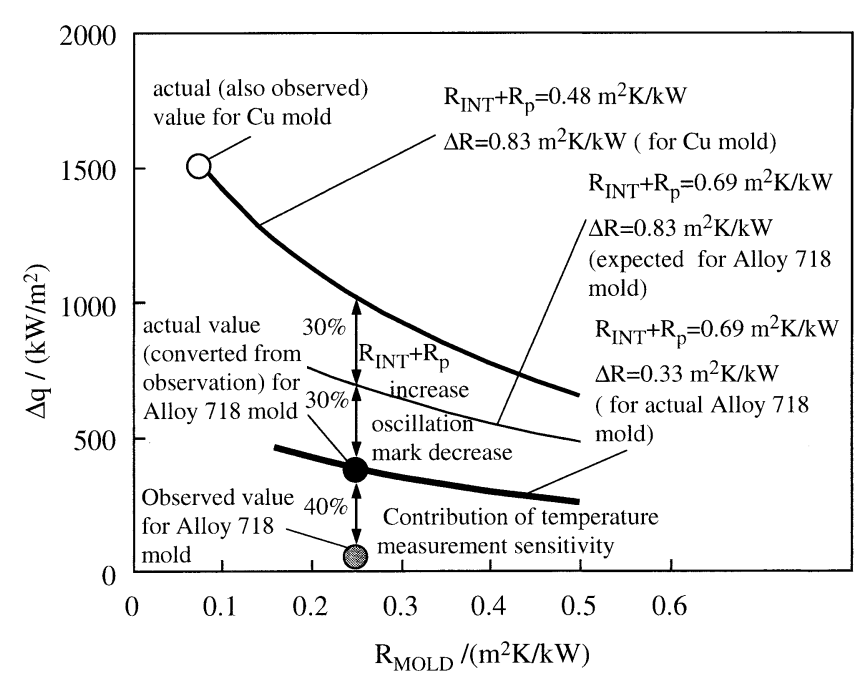

Fig. 15. Comparison of observed and calculated heat flux fluctuation immediately below meniscus. (The observed fluctuation of heat flux, $\Delta q$, equals $2 \sigma$ at each peak of observed heat flux in Fig. 5. The actual $\Delta q$ for the Alloy 718 mold is the product of the observed $\Delta q$ and $\beta_{\mathrm{Cu}} / \beta_{718}$. The curves in the above figure were calculated from estimated $R_{\mathrm{INT}}+R_{\mathrm{p}}$ and Eq. (3).)

$$
\frac{\beta_{718}}{\beta_{\mathrm{Cu}}}=\frac{0.0881}{0.6143}=0.146
$$

Here, $\alpha_{718}=3.97 \times 10^{-6} \mathrm{~m}^{2} \mathrm{~s}^{-1}, x_{718}=3.50 \times 10^{-3} \mathrm{~m}, \alpha_{\mathrm{Cu}}=$ $9.28 \times 10^{-5} \mathrm{~m}^{2} \mathrm{~s}^{-1}, x_{\mathrm{Cu}}=5.00 \times 10^{-3} \mathrm{~m}$.

Therefore, for an identical temperature change input having a cycle of approximately $0.5 \mathrm{~s}$, the amplitude of the temperature swing that can be obtained with the Alloy 718 is only about $15 \%$ of that of the $\mathrm{Cu}$ mold. Thus, if the Alloy 718 mold is evaluated under the same conditions as the $\mathrm{Cu}$ mold, the true value of the fluctuation in heat flux (i.e. temperature fluctuation) which is attributable to the Alloy 718 mold can be estimated to be approximately 7 times larger than the observed value, or approximately $0.41 \mathrm{MW} \mathrm{m}^{-2}$.

Figure 15 shows the relationship between $R_{\mathrm{MOLD}}$ and $\Delta q$ with the $\mathrm{Cu}$ mold $\left(R_{\mathrm{INT}}+R_{\mathrm{p}}=0.48 \mathrm{~m}^{2} \mathrm{~K} / \mathrm{kW}\right)$ and the Alloy 718 mold $\left(R_{\mathrm{INT}}+R_{\mathrm{p}}=0.69 \mathrm{~m}^{2} \mathrm{~K} / \mathrm{kW}\right)$ when $\Delta R=0.83 \mathrm{~m}^{2}$ $\mathrm{K} / \mathrm{kW}$ in Eq. (3). From Fig. 15, an estimated value of 0.71 MW m ${ }^{-2}$ can be obtained for the $\Delta q$ of the Alloy 718 mold on the assumption that $\Delta R=0.83 \mathrm{~m}^{2} \mathrm{~K} / \mathrm{kW}$. However, this value is substantially larger than the $0.40 \mathrm{MW} \mathrm{m}^{-2}$ estimated from the observed values. From Eq. (3), the value of $\Delta R$ at which $\Delta q$ becomes $0.40 \mathrm{MW} \mathrm{m}^{-2}$ is $0.33 \mathrm{~m}^{2} \mathrm{~K} / \mathrm{kW}$. As previously mentioned, there is an upper limit on the changes in $R_{\mathrm{INT}}$, which means that even large values of $R_{\mathrm{INT}}$ must be on the order of $0.1 \mathrm{~m}^{2} \mathrm{~K} / \mathrm{kW}$. Hence, it must inevitably be concluded that $\Delta R$ is mainly attributable to fluctuations in the thickness of the mold flux film. As mentioned above, on the assumption that the thermal conductivity of the mold flux film is $1.0 \mathrm{~W} \mathrm{~m}^{-1} \mathrm{~K}^{-1},{ }^{15}$ ) the fluctuation in the thickness of the film is $0.83 \mathrm{~mm}$ with the $\mathrm{Cu}$ mold and $0.33 \mathrm{~mm}$ with the Alloy 718 mold, which is in good agreement with the deviation of $2 \sigma$ in the slab oscillation mark depth at $t_{\mathrm{N}}=0.15 \mathrm{~s}$ in Fig. 13. (This deviation value is equivalent to $0.8 \mathrm{~mm}$ with the $\mathrm{Cu}$ mold and $0.3 \mathrm{~mm}$ with the Alloy 718 mold.) From the above, the contribution of each thermal resistance factor to the reduction in fluctuations in heat removal, $\Delta q$ in these casting experiments is considered to be approximately $40 \%$ from mold thermal resistance, approximately $30 \%$ from the increase in mold flux film thickness resulting from the increase in mold thermal resistance, and approximately $30 \%$ from factors associated with the reduction in oscillation mark depth which is realized by mild cooling (Fig. 15). The reason of the mark depth reduction os assumed that starting point of the shell solidification shhifts beneath with the mild cooling as well as the hook depth.

The analysis in this section has focused on time-series fluctuations in heat flux. However, this type of fluctuation is also thought to have an important influence on non-uniform cooling in the transverse direction, which is a major factor in longitudinal cracking. The oscillation mark on the slab surface in actual continuous caster are definitely not straight, indicating that the start of solidification does not occur at the same depth across the mold width. This in turn suggests that non-uniform heat removal in the transverse direction is frequently encouraged by the passage of oscillation mark. In this case, the Alloy 718 mold, which this work has shown to be effective in reducing the frequently and depth of oscillation mark, would represent one solution to the problem of achieving uniform cooling in the mold width direction.

\section{Conclusion}

A mild cooling mold of Alloy 718 has been designed, fabricated, and used in casting experiments with mediumcarbon steel in a laboratory continuous caster with no problems of mold wear or other casting-related problems. This work showed that the Alloy 718 mold offers the following advantages over the conventional $\mathrm{Cu}$ mold.

(1) Heat removal by the mold was reduced by $40 \%$ from the heat flux measurement and secondary dendrite arm spacing.

(2) Fluctuations over time for heat flux were reduced to approximately $1 / 4$, when the heat response of the mold was considered.

(3) As a result of the reduction in heat removal by the mold, the index of longitudinal surface crack length was reduced by $50 \%$.

(4) The frequency of hooks at overflow type oscillation marks was reduced by $50 \%$.

(5) The depth of the hooks that occurred at oscillation marks was reduced by $30-40 \%$.

(6) The deviation in the depth of oscillation marks was reduced, and the average depth of marks was reduced by approximately $40 \%$.

These results have confirmed that the mild cooling method using the Alloy 718 mold is effective in suppressing longitudinal cracks and hooks, which are a capture sites for inclusions.

\section{REFERENCES}

1) A. Grill and J. K. Brimacombe: Ironmaking Steelmaking, 3 (1976), 2,76 .

2) K. Nakai, T. Sakashita, M. Hashio, M. Kawasaki, K. Nakajima and Y. Sugitani: Tetsu-to-Hagané, 73 (1987), 498.

3) T. Tanaka, Y. Nuri, T. Egashira, R. Arima and T. Ohashi: Tetsu-to- 
Hagané, 68 (1982), S159.

4) T. Fujiyama, S. Miyagawa, S. Deshimaru and H. Mizota: 68th Steelmaking Conf. Proc., ISS, AIME, Warrendale, PA, (1985), 215.

5) M. Suzuki, R. Yamaguchi, K. Murakami and H. Murakami: CAMPISIJ, 5 (1992), 1217.

6) H. Shimakage, E. Anzai, R. Kanno, T. Naruse, M. Tani and K. Miyazawa: CAMP-ISIJ, 13 (2000), 815.

7) H. Nakato, M. Ozawa, K. Kinoshita, Y. Habu and T. Emi: Tetsu-toHagané, 67 (1981), 1200.

8) T. Sakuraya, T. Emi, T. Imai, K. Emoto and M. Kodama: Tetsu-toHagané, 67 (1981), 1220.

9) T. Chikano, K. Ichikawa and O. Nomura: Shinagawa Tech. Rep., 31 (1988), 75

10) H. Tomono, W. Kurz and W. Heinemann: Metall. Trans., 12B (1981),
409.

11) T. Emi, H. Nakato, Y. Iida, K. Emoto, R. Tachibana, T. Imai and H. Bada: 61st Steelmaking Conf. Proc., ISS, Warrendale, PA, (1978), 350 .

12) H. Mizukami, T. Okamura, S. Izumi and R. Kusakawa: Tetsu-toHagané, 74 (1988), 1609.

13) J. Cho, H. Shibaa, T. Emi and M. Suzuki: ISIJ Int., 38 (1998), 440.

14) K. Watanabe, M. Suzuki, K. Murakami, H. Kondo, A. Miyamoto and T. Shiomi: Tetsu-to-Hagané, 83 (1997), 115.

15) A. Yamauchi, K. Sorimachi, T. Sakuraya and T. Fujii: ISIJ Int., 33 (1993), 140.

16) Mill sheet of Alloy 718 (Incolel 718) of Daido Steel, (1990).

17) A. Suzuki, T. Suzuki, Y. Nagaoka and S. Iwata: J. Jpn. Inst. Met, 32 (1968), 1301. 